\title{
An Approach To Forecasting The Demand for Urban Land\#
}

\author{
Michael W. Babcock*
}

In recent years there has been a heightened interest in the management of local growth in general and in land use planning specifically. Local government decision makers would like to know what economic factors affect the local demand for land as well as what growth is likely to occur in the future. If local government policy instruments have substantial leverage on the important causative factors, then the government can affect the amount of growth that takes place. If local government decision makers have reliable growth forecasts, they can use what policy instruments they have to manage the growth that is expected to occur.

Regional economic theory suggests that local government has little control over the amount of growth that occurs. This depends on the local and external demand for local production, which basically is in the hands of private decision makers. However, local government has a great deal of control over the location of growth. Zoning controls, transportation investment, and extension of utilities are powerful instruments for managing growth that does occur. Accordingly if local authorities have reliable forecasts of the demand for urban land they can formulate plans to effectively manage urban growth. Also the forecasts would be helpful in indicating future needs for local public goods and for predicting changes in tax base.

The model presented in this paper is a framework for (a) identifying the economic factors affecting the demand for urban land and (b) developing conditional forecasts of the demand for urban land.

\section{THE MODEL}

Before discussing the model in detail, a few general comments are in order. In formulating the model, the major consideration was predictive ability. Most would agree that the two major goals of any model are explanation and prediction. Unfortunately, these two goals often turn out to be mutually exclusive. Very sophisticated theoretical models often prove impossible to implement empirically. In contrast, simple models often are capable of providing accurate forecasts while contributing little to an understanding of the underlying relationships.

These considerations affect the selection of the model's independent

\#Computer programming for the study was performed by Alan H. Ringleb, Kansas State University.

* Kansas State University, Manhattan, Kansas. 
variables. The independent variables selected have a theoretical relationship with the dependent variable, but they are also forecastable. By that I mean that both the methodology and the data exist to forecast the independent variables.

Also the model is concerned with forecasting the quantity of land demanded. This approach differs from most previous economic research on land use which has been primarily concerned with (a) the determinants of land values (b) the intraurban location of various classes of economic activity (c) the effects of zoning and (d) measurement of density gradients. Thus the model is primarily concerned with the dispersion changes that accompany growth rather than density.

The conceptual approach employed in formulating the model is to view land as a factor of production. Like all other factors of production, the demand for the factor is derived from the demand for goods and services. Thus, a community's demand for land will be derived from the demand for locally produced goods and services. An increase in the demand for local production will increase the demand for land. Thus, if variables that reflect the demand for local production can be identified, then the demand for land can be estimated.

The model was estimated using Manhattan, Kansas as the study area. Manhattan is an excellent case study for empirical estimation of the model since it has experienced rapid growth in the past 20 years. Employment has increased by nearly $100 \%$ and the land area has more than doubled. Manhattan is also somewhat of a special case since it is the home of Kansas State University (K.S.U.) which like most universities has grown rapidly during the past two decades. However, the general considerations that lead to the specification of the model are valid for any community. That is, the growth of the demand for the output of the cities' economic base industries will have a fundamental impact on the demand for land.

The model consists of time series multiple regression equations for the principal types of land use. The equations used to estimate the demand for the different categories of land are as follows:

(1) $\mathrm{A}_{\mathrm{T}}=\mathrm{B}_{1}+\mathrm{B}_{2} \mathrm{~N}+\mathrm{B}_{3} \mathrm{E}+\mathrm{B}_{4} \mathrm{C}+\mathrm{B}_{5} \mathrm{~T}$

(2) $\mathrm{A}_{\mathrm{R}}=\mathrm{B}_{1}+\mathrm{B}_{2} \mathrm{~N}+\mathrm{B}_{3} \mathrm{E}+\mathrm{B}_{4} \mathrm{C}+\mathrm{B}_{5} \mathrm{~T}$

(3) $\mathrm{A}_{\mathrm{C}}=\mathrm{B}_{1}+\mathrm{B}_{2} \mathrm{~N}+\mathrm{B}_{3} \mathrm{E}+\mathrm{B}_{4} \mathrm{C}+\mathrm{B}_{5} \mathrm{~T}$

(4) $\mathrm{A}_{\mathrm{I}}=\mathrm{B}_{1}+\mathrm{B}_{2} \mathrm{~N}_{\mathrm{I}}+\mathrm{B}_{3} \mathrm{~N}[\mathrm{US}]_{\mathrm{I}}+\mathrm{B}_{4} \mathrm{~T}$

(5) $\mathrm{A}_{\mathrm{P}}=\mathrm{B}_{1}+\mathrm{B}_{2} \mathrm{~N}+\mathrm{B}_{3} \mathrm{E}+\mathrm{B}_{4} \mathrm{C}+\mathrm{B}_{5} \mathrm{~T}$

$A_{T}$ - Total number of acres of developed land [includes developed K.S.U. campus land]

$A_{R}$ - Total acres of residential land

$A_{C}$ - Total acres of commercial land

$A_{I}$ - Total acres of industrial land 
$A_{P}$ - Total acres of public land [includes area occupied by city streets but does not include K.S.U. campus area]

N - Total Riley County non-agricultural civilian employment ${ }^{1}$

$\mathrm{N}_{\mathrm{I}}$ - Riley County non-agricultural industrial employment [includes wage and salary employment in the manufacturing, transportation, and public utility sectors]

$\mathrm{N}[\mathrm{US}]_{\mathrm{I}}$ - National non-agricultural industrial employment [includes wage and salary employment in the manufacturing, transportation, and public utility sectors]

E - K.S.U. total enrollment - fall semester

C - Kansas per capita car registration [includes private and public autos only, exc. military $]^{2}$

$\mathrm{T}$ - Time

Several variables could be used to reflect the demand for local production. When the demand for local goods and services increases; output, population, and employment would all increase. Employment was selected as an independent variable in (1) because employment data are more readily available for local areas. Higher education is a dominant economic base industry in the study area. Enrollment was selected as a good measure of the state, national, and international demand for locally produced higher education services. Independent variable $\mathrm{E}$ should be positively correlated to the dependent variable in (1). Car registration per capita was included in (1) as a proxy variable for transportation costs [See Muth 1961, p. 216]. An increase in transportation costs would have the effect of reducing the radial expansion of the city and increasing density. The theoretically expected sign between $\mathrm{C}$ and $\mathrm{A}_{\mathrm{T}}$ would be positive since an increase in transportation costs would reduce autos per capita [C] and the quantity of land demanded $\left[\mathrm{A}_{\mathrm{T}}\right]$. The time variable is included in (1) as a proxy for variables that could have an effect on the demand for land but are difficult to quantify. For example, slow changes in the production function caused by technical change.

The rationale for the inclusion of independent variables $\mathrm{N}, \mathrm{E}, \mathrm{C}$, and $\mathrm{T}$ in the other equations is basically the same as for (1). The demand for land by the commercial sector is hypothesized to depend on the demand for the goods and services produced by that sector. According to the economic base theory of local growth, the demand for non-base output is primarily a function of local income. Since local income data are not available, variable $\mathrm{N}$ (total employment) was used as a proxy for local income. Of course as total employment $[\mathrm{N}]$ increases the demand for land by the commercial sector should increase. The economic base theory also contends that growth in the base sector will have a multiplier effect on non-base [commercial] activity. Since Kansas State University is the largest base industry in the area, variable E (enrollment) should also be positively correlated with demand for land by the commercial sector. 
The demand for land by the industrial sector will be positively related to the demand for industrial sector output. An increase in the demand for industrial sector output will lead to an increase in industrial sector employment. Thus, independent variable $\mathrm{N}_{\mathrm{I}}$ should be positively correlated to the dependent variable in (4). Independent variable $\mathrm{N}[\mathrm{US}]_{\mathrm{I}}$ was included on the premise that demand changes that affect the industrial sector nationally will also affect the local industrial sector in like manner. Admitting the possibility of differential regional growth in the national industry, $\mathrm{N}[\mathrm{US}]_{\mathrm{I}}$ should be positively correlated to the dependent variable in (4).

\section{RESULTS OF THE MODEL}

The model was estimated using data from the 1960-1976 time period. The data for the dependent variables was obtained by using city lot maps in conjunction with the city directory. Data sources for the independent variables may be found in the footnotes. ${ }^{3}$

The model equations were estimated using the stepwise regression procedure. The Durbin-Watson test for equations $A_{T}$ and $A_{P}$ indicated no significant autocorrelation. The test for equations $A_{R}$ and $A_{I}$ was inconclusive. Equation $A_{C}$ had significant positive autocorrelation. Correcting for serial correlation should result in improved forecasting performance since it reduces the standard error of forecast if $\rho$ is known [See Pindyck and Rubinfeld 1976, p. 172]. However, in practice $\rho$ is not known. In cases where the sample size is small [approximately 20], Rao and Griliches have suggested the following rule of thumb. One should use methods that correct for autocorrelation if $|\hat{\rho}| \geqslant .3$, where $\hat{\rho}$ is the estimated first order serial correlation from an OLS regression [See Maddala 1977, p. 283]. Since $\hat{\rho}$ exceeded .3 for $A_{R}, A_{C}$, and $A_{I}$, they were all corrected for serial correlation using the Hildreth-Lu procedure [See Pindyck and Rubinfeld 1976, p. 112]. The equations that satisfied the Durbin-Watson test and minimized the standard error of the regression were then selected.

The correction for autocorrelation improved the fit of equations $A_{R}, A_{C}$, and $A_{I}$. Table 3 compares the actual values of $A_{R}, A_{C}$, and $A_{I}$ with the fitted values using OLS without serial correlation correction. Table 2 compares the actual values with the fitted values using the Hildreth-Lu transformed equations [in Table 1]. For $A_{R}$, the Hildreth-Lu equation produced a better fit for twelve of sixteen possible cases; for $A_{C}$, ten of sixteen with two ties; for $A_{I}$, ten of sixteen.

The AAE [average absolute error] was also calculated [See Maddala 1977 , p. 347]. For $A_{R}$, the AAE of the Hildreth-Lu estimates was 22.3 as opposed to 30.9 for OLS. In the case of $A_{C}$, the AAE for the Hildreth-Lu estimates was 7.3; 9.3 for OLS. For $\mathrm{A}_{\mathrm{I}}$, AAE of the OLS estimates was 6.0; 4.4 for the Hildreth-Lu equations.

Therefore the fit of the equations and the probable forecast performance were improved by correcting for serial correlation.

The estimated equation for all five land use categories are in Table 1. An examination of equation $\mathrm{A}_{\mathrm{T}}$ indicated that independent variables $\mathrm{N}$ and $\mathrm{T}$ 
have the expected sign and are significant. Independent variable $C$ is significant but has the wrong sign. One possible explanation for this could be multicollinearity. An examination of the correlation matrix revealed that the partial correlation coefficients between almost all of the independent variables are quite high. Unfortunately no reliable test exists for determining whether multicollinearity is a significant problem. There are only rules of thumb and these often lead to conflicting conclusions [see Maddala 1977, p. 188].

Multicollinearity could also be a problem in equation $A_{R}$. Independent variables $\mathrm{N}$ and $\mathrm{E}$ have the expected positive sign but are not significant. This is a common indicator of multicollinearity. Only variable $T$ is significant in equation $A_{R}$. Multicollinearity may also be a problem in equation $A_{C}$. Variable $N$ has the expected positive sign but is not significant. Variable $T$ has the expected positive sign and is significant.

An examination of equation $A_{I}$ indicates that variables $N_{I}$ and $T$ have the expected positive sign and both are significant. The results of equation $A_{P}$ are similar to equation $A_{T}$. Variables $N$ and $T$ have the expected sign and are significant. Variable $\mathrm{C}$ is significant but has the wrong sign. Again a possible explanation could be multicollinearity.

The fit of all the equations is quite good with generally high $\mathrm{R}^{2}$ 's. The probable existence of multicollinearity in the equations made precise iden-

TABLE 1.

Estimated Land Demand Equations

\begin{tabular}{|c|c|c|c|c|c|c|c|}
\hline \multirow[b]{2}{*}{$\begin{aligned}= & -5057 \\
& (-10.67)\end{aligned}$} & \multicolumn{4}{|c|}{ Total Area Equation } & \multirow{2}{*}{$\frac{\mathrm{R}^{2}}{.99}$} & \multirow{2}{*}{$\frac{\text { Sy } ・ x}{43.29}$} & $\mathrm{~d}$ \\
\hline & $\begin{array}{c}+.07659 \mathrm{~N}^{* *}- \\
(3.105)\end{array}$ & $\begin{array}{c}2665 \mathrm{C}^{*} \\
(-2.567)\end{array}$ & + & $\begin{array}{c}127.2 \mathrm{~T}^{* *} \\
(8.20)\end{array}$ & & & 1.9 \\
\hline
\end{tabular}

Residential Area Equation

$$
\mathrm{A}_{\mathrm{R}}=\underset{(-2.058)}{-551.8}+\underset{(.36)}{.00896 \mathrm{~N}}+\underset{(.31)}{.00903 \mathrm{E}}+\underset{(2.3)}{58.2 \mathrm{~T}^{*}} .81 \quad 35.361 .74
$$

Commercial Area Equation

\begin{tabular}{|c|c|c|c|c|c|c|c|}
\hline$A_{1}=$ & $\begin{array}{c}-168.5 \\
(-3.0)\end{array}$ & $\begin{array}{c}.00617 \mathrm{~N} \\
(.87)\end{array}$ & + & $\begin{array}{c}7.537 \mathrm{~T}^{*} \\
(2.28)\end{array}$ & .81 & 9.98 & 1.66 \\
\hline \multicolumn{8}{|c|}{ Industrial Area Equation } \\
\hline$A_{1}=$ & $\begin{array}{l}-143.5 \\
(-5.336)\end{array}$ & $+\underset{(1.92}{.02457 \mathrm{~N}_{\mathrm{I}}}$ & + & $\begin{array}{c}7.782 \mathrm{~T}^{* * *} \\
(5.78)\end{array}$ & .83 & 6.47 & 1.72 \\
\hline
\end{tabular}

Public Area Equation

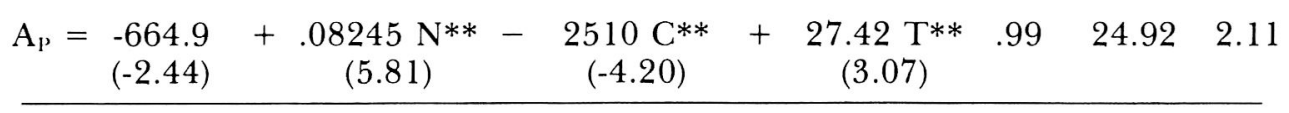

* Significant at the .05 level

** Significant at the .01 level 
TABLE 2.

Comparison of Fitted Values to Actual Values-Hildreth-Lu Estimates

\begin{tabular}{|c|c|c|c|c|c|c|c|c|c|}
\hline Yeấr & $A_{R}$ & $\hat{A}_{R}$ & $\% \triangle$ & $\mathrm{A}_{\mathrm{C}}$ & $\hat{\mathrm{A}}_{C}$ & $\% \triangle$ & $\mathrm{A}_{\mathrm{I}}$ & $\hat{A}_{I}$ & $\% \triangle$ \\
\hline 1961 & 1130 & 1130 & 0 & 84 & 97 & +15.4 & 45 & 41 & -8.8 \\
\hline 1962 & 1157 & 1167 & +.8 & 84 & 103 & +22.6 & 46 & 44 & -4.3 \\
\hline 1963 & 1277 & 1196 & -6.3 & 125 & 107 & -14.4 & 46 & 48 & +4.3 \\
\hline 1964 & 1299 & 1310 & +.8 & 147 & 135 & -8.1 & 53 & 50 & -5.6 \\
\hline 1965 & 1338 & 1344 & +.4 & 159 & 154 & -3.1 & 53 & 56 & +5.6 \\
\hline 1966 & 1370 & 1386 & +1.1 & 176 & 165 & -6.2 & 54 & 60 & +11.1 \\
\hline 1967 & 1417 & 1426 & +.6 & 178 & 183 & +2.8 & 63 & 65 & +3.1 \\
\hline 1968 & 1455 & 1483 & +1.9 & 194 & 190 & -2.0 & 64 & 71 & +10.9 \\
\hline 1969 & 1520 & 1525 & +.3 & 200 & 204 & +2.0 & 70 & 74 & +5.7 \\
\hline 1970 & 1550 & 1579 & +1.8 & 206 & 204 & $-\quad .9$ & 74 & 81 & +9.4 \\
\hline 1971 & 1604 & 1626 & +1.3 & 211 & 216 & +2.3 & 99 & 100 & +1.0 \\
\hline 1972 & 1658 & 1678 & +1.2 & 217 & 223 & +2.7 & 124 & 109 & -12.0 \\
\hline 1973 & 1726 & 1731 & +.2 & 222 & 229 & +3.1 & 126 & 128 & +1.5 \\
\hline 1974 & 1866 & 1808 & -3.1 & 238 & 238 & 0 & 137 & 131 & -4.3 \\
\hline 1975 & 1975 & 1933 & -2.1 & 251 & 248 & -1.1 & 143 & 142 & \\
\hline 1976 & 2009 & 2025 & +.7 & 256 & 259 & +1.1 & 144 & 150 & +4.1 \\
\hline
\end{tabular}

$\% \Delta=\frac{\hat{\mathrm{A}}_{\mathrm{t}}-\mathrm{A}_{\mathrm{t}}}{\mathrm{A}_{\mathrm{t}}}$ 
TABLE 3.

Comparison of Fitted Values to Actual Values - OLS Estimates

\begin{tabular}{|c|c|c|c|c|c|c|c|c|c|}
\hline Year & $A_{R}$ & $\hat{A}_{R}$ & $\% \triangle$ & $\mathrm{A}_{\mathrm{C}}$ & $\hat{\mathrm{A}}_{\mathrm{C}}$ & $\% \triangle$ & $\mathrm{A}_{\mathrm{I}}$ & $\hat{A}_{I}$ & $\% \triangle$ \\
\hline 1960 & 1111 & 1066 & -4.0 & 83 & 88 & +6.0 & 44 & 27 & -38.6 \\
\hline 1961 & 1130 & 1133 & $\begin{array}{r}. \\
+\quad .2\end{array}$ & 84 & 100 & +19.0 & 45 & 38 & -15.5 \\
\hline 1962 & 1157 & 1188 & +2.6 & 84 & 110 & +30.9 & 46 & 43 & -6.5 \\
\hline 1963 & 1277 & 1218 & -4.6 & 125 & 123 & -1.6 & 46 & 51 & +10.8 \\
\hline 1964 & 1299 & 1293 & -.4 & 147 & 134 & -8.8 & 53 & 57 & +7.5 \\
\hline 1965 & 1338 & 1357 & +1.4 & 159 & 145 & -8.8 & 53 & 57 & +7.5 \\
\hline 1966 & 1370 & 1401 & +2.2 & 176 & 159 & -9.6 & 54 & 56 & +3.7 \\
\hline 1967 & 1417 & 1428 & +.7 & 178 & 173 & -2.8 & 63 & 63 & 0 \\
\hline 1968 & 1455 & 1458 & +.2 & 194 & 184 & -5.1 & 64 & 67 & +4.6 \\
\hline 1969 & 1520 & 1479 & -2.6 & 200 & 195 & -2.5 & 70 & 71 & +1.4 \\
\hline 1970 & 1550 & 1596 & +2.9 & 206 & 205 & -.4 & 74 & 84 & +13.5 \\
\hline 1971 & 1604 & 1655 & +3.1 & 211 & 212 & $+\quad .4$ & 99 & 117 & +18.1 \\
\hline 1972 & 1658 & 1699 & +2.4 & 217 & 211 & -2.7 & 124 & 117 & -5.6 \\
\hline $197 \overline{3}$ & 1726 & 1753 & +1.5 & 222 & 225 & +1.3 & 126 & 114 & $\begin{array}{r}9.0 \\
-9.5\end{array}$ \\
\hline 1974 & 1866 & 1807 & -3.1 & 238 & 236 & -.8 & 137 & 118 & -13.8 \\
\hline 1975 & 1975 & 1926 & -2.4 & 251 & 258 & +2.7 & 143 & 142 & -.6 \\
\hline 1976 & 2009 & 1991 & -.8 & 256 & 275 & +7.4 & 144 & 144 & 0 \\
\hline
\end{tabular}

$\% \Delta=\frac{\hat{\mathrm{A}}_{\mathrm{t}}-\mathrm{A}_{\mathrm{t}}}{\mathrm{A}_{\mathrm{t}}}$ 
tification of some of the structural parameters impossible. However, this is not a serious impediment to the primary objective of the model which is prediction. The predictive ability of the equations will remain intact as long as multicollinearity continues into the prediction period [See Kelejian and Oates 1974, p. 189].

\section{FORECASTING MODELS OF THE INDEPENDENT VARIABLES}

An ex ante forecast predicts the value of the dependent variable beyond the estimation period. In the case of unlagged models such as this one, the values of the independent variables are often not known. Therefore they must be estimated. Referring to Table 1, there are four independent variables in the estimated equations that must be forecast $-\mathrm{N}, \mathrm{N}_{\mathrm{I}}, \mathrm{E}$, and $\mathrm{C}$. Forecasting models for these variables were developed and an ex ante forecast was made for 1977.

The forecasting model for $\mathrm{N}$ is as follows.

(6) $\mathrm{N}=\mathrm{B}_{0}+\mathrm{B}_{1} \mathrm{E}+\mathrm{B}_{2} \mathrm{~N}[\mathrm{~K}]+\mathrm{B}_{3} \mathrm{~N}[\mathrm{US}]+\mathrm{B}_{4} \mathrm{~T}$

$\mathrm{N}$ - Total Riley county non-agricultural civilian employment

E - Total K.S.U. enrollment - fall semester

$\mathrm{N}[\mathrm{K}]$ - Total Kansas civilian employment

$\mathrm{N}$ [US] - Total U.S. non-agricultural wage and salary employment

$\mathrm{T}$ - Time

The local demand for labor is derived from the demand for locally produced output. The demand for community output in turn depends on local and external demand. Independent variable $\mathrm{E}$ was selected to represent regional and national demand for locally produced higher education services. $\mathrm{N}[\mathrm{K}]$ was selected as a proxy variable for regional demand for local output. N[US] represents the strength of national demand for community production. The time variable was included as a proxy for other influences on local employment which are difficult to quantify and forecast. These influences might include changes in supply side variables like technical change and shifts in regional input costs. All of the independent variables should be positively correlated to the dependent variable.

The forecasting model for $\mathrm{N}_{\mathrm{I}}$ is as follows:

(7) $\mathrm{N}_{\mathrm{I}}=\mathrm{B}_{0}+\mathrm{B}_{1} \mathrm{~N}[\mathrm{US}]+\mathrm{B}_{2} \mathrm{~N}[\mathrm{US}]_{\mathrm{I}}+\mathrm{B}_{3} \mathrm{~T}$

$N_{I}$ - Riley county non-agricultural industrial employment

$\mathrm{N}$ [US] - Total U.S. non-agricultural wage and salary employment

$\mathrm{N}[\mathrm{US}]_{1}$ - National non-agricultural industrial employment [includes wage and salary employment in the manufacturing, transportation, and public utility sectors]

$\mathrm{T}$ - Time 
Industrial sector employment depends primarily upon demand which is external to the region. Independent variables $\mathrm{N}[\mathrm{US}]$ and $\mathrm{N}[\mathrm{US}]_{1}$ reflect the strength and nature of national demand for local industrial output. Time was included in (7) for basically the same reasons as for (6). The expected sign of the independent variables is positive.

The forecasting model for independent variable $\mathrm{E}$ is as follows:

(8) $\mathrm{E}=\mathrm{B}_{\mathrm{O}}+\mathrm{B}_{1} \mathrm{E}[\mathrm{REG}]+\mathrm{B}_{2} \mathrm{E}[\mathrm{SEN}]+\mathrm{B}_{3} \mathrm{~T}$

E - K.S.U. total enrollment - fall semester

E[REG] - Opening fall enrollment of degree credit students - Kansas Regents' Institutions

$\mathrm{E}[\mathrm{SEN}]$ - Total 12th grade enrollment in Kansas high schools - Close of school year

$\mathrm{T}$ - Time

A wide variety of economic and non-economic factors affect higher education enrollment. Basically it depends on the size of the client population and the propensity of that population to enroll. However, measuring either of these is fraught with difficulty. E[SEN] was included as a measure of part of the client population. $E[R E G]$ was included on the premise that K.S.U. enrollment is a predictable share of enrollment in Kansas Regents' institutions. Time could reflect some of the factors affecting the propensity to enroll. The expected sign of all the independent variables is positive.

Independent variable $\mathrm{C}$, per capita auto registration, was forecast in two parts. The forecasting model for auto registrations is as follows:

(9) $\mathrm{K}[\mathrm{AREG}]=\mathrm{B}_{0}+\mathrm{B}_{1} \mathrm{Y}[\mathrm{K}]=\mathrm{B}_{2} \mathrm{~T}$

$\mathrm{K}$ [AREG] - Kansas auto registration [includes private and public autos only, exc. military]

$\mathrm{Y}[\mathrm{K}]$ - Kansas personal income, measured in millions of current dollars

$\mathrm{T}$ - Time

The forecasting model for K[AREG] is based on the premise that the demand for autos is primarily a function of income. The expected sign of the indepentent variables is positive. Kansas population was forecast on the basis of past growth rates.

\section{ESTIMATED EQUATIONS OF THE INDEPENDENT VARIABLES}

The equations for the independent variables were estimated for the time period 1960-1976. Data sources can be found in the footnotes. ${ }^{4}$ The equations were estimated using stepwise regression procedure. The estimated equations are found in Table 4. 
An examination of Table 4 indicates that the fit of the total employment $(\mathrm{N})$ equation is very good with an $\mathrm{R}^{2}$ of .99 . Also there is no significant serial correlation. The independent variables have the expected sign except for $\mathrm{N}[\mathrm{K}]$. The negative sign of $\mathrm{N}[\mathrm{K}]$ and the non-significance of $\mathrm{E}$ are possibly due to multicollinearity. $\mathrm{N}[\mathrm{US}]$ has the expected positive sign and is significant.

The forecasting equation for $\mathrm{N}_{\mathrm{I}}$ also has a good fit with an $\mathrm{R}^{2}$ of .83 . There is no significant serial correlation. $\mathrm{N}[\mathrm{US}]$ has the expected positive sign and is significant. The sign of $\mathrm{N}[\mathrm{US}]_{\mathrm{I}}$ is negative and significant. As explained above, the expected sign is positive. However, the sign could be negative if the particular mix of local industries has a cyclical pattern that runs counter to the national industrial sector. Examination of the data reveals that in several of the years in the estimation period $\mathrm{N}_{\mathrm{I}}$ and $\mathrm{N}[\mathrm{US}]_{\mathrm{I}}$ changed in the opposite direction.

The forecasting equation for enrollment $[\mathrm{E}]$ has an excellent fit with an $\mathrm{R}^{2}$ of .99. There is no significant autocorrelation. Independent variables $\mathrm{E}[\mathrm{REG}]$ and $\mathrm{T}$ both have the expected positive sign and are significant. The expected sign of $\mathrm{E}[\mathrm{SEN}]$ was hypothesized to be positive. However, the sign is negative and the variable is significant. An examination of the data reveals that $\mathrm{E}[\mathrm{SEN}]$ peaked in 1971 and has declined slightly since then. However, K.S.U. enrollment has continued to increase during this period. This could be due to several possible factors. One of these could be that a larger fraction of seniors from Kansas high schools are enrolling in K.S.U. than was previously the case. It could also be due to increased enrollments by persons outside the traditional client groups. In any event this could explain the negative sign of $\mathrm{E}[\mathrm{SEN}]$.

\section{TABLE 4.}

Forecasting Equations - Independent Variables

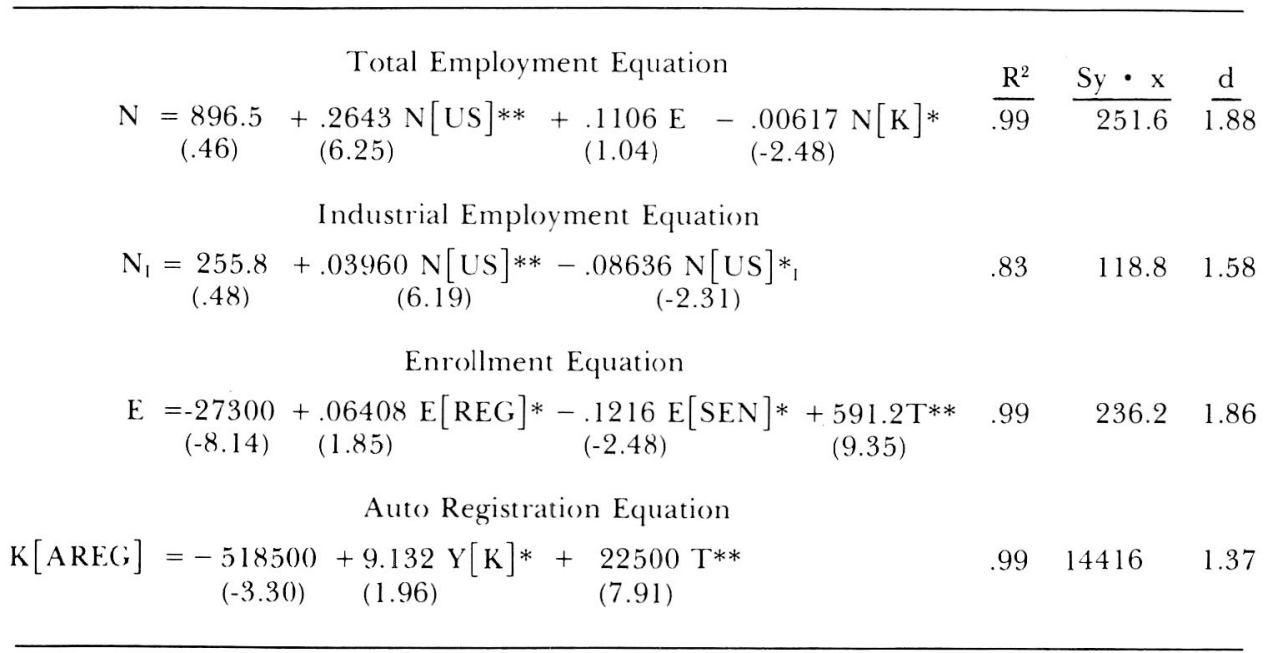

** Significant at .01 level.

* Significant at .05 level. 
The Kansas auto registration equation has an excellent fit with an $\mathrm{R}^{2}$ of .99. Both $\mathrm{Y}[\mathrm{K}]$ and $\mathrm{T}$ have the expected positive sign and are significant. However, the Durbin-Watson statistic fell in the inconclusive range of the $5 \%$ limits. The Hildreth-Lu method was performed on the equation to determine if the fit of the equation could be improved by correcting for serial correlation. The test indicated a $\hat{\rho}$ of .3. As indicated above, Rao and Griliches suggest correcting for serial correlation if $|\hat{\rho}|$ is $\geqslant .3$ when the sample size is small [approximately 20]. The sample for the equation is 15 . However, the standard error of the OLS equation is slightly lower than the Hildreth-Lu equation. Therefore, the OLS equation was accepted.

\section{THE 1977 EX ANTE FORECAST}

To test the predictive performance of the land use forecasting system an ex ante forecast was performed for 1977. This was done as follows:

(1) The actual 1977 values of $A_{T}, A_{R}, A_{C}, A_{I}$, and $A_{P}$ were measured.

(2) The 1977 values of $\mathrm{N}, \mathrm{N}_{\mathrm{I}}, \mathrm{E}$, and $\mathrm{C}$ were forecast using equations 6 through 9 .

(3) The forecast values of $\mathrm{N}, \mathrm{N}_{\mathrm{I}}, \mathrm{E}, \mathrm{C}$, and $\mathrm{T}$ were inserted where appropriate in equations 1 through 5 to obtain 1977 forecasts of $A_{T}, A_{R}, A_{C}, A_{I}$, and $A_{P}$.

(4) The forecast values of land use obtained in (3) were then compared to the actual values as measured in (1).

The 1977 actual values of land use were measured in the same manner as for the 1960-1976 period. Procedures for obtaining 1977 forecasts for $\mathrm{N}, \mathrm{N}_{\mathrm{I}}, \mathrm{E}$, and $\mathrm{C}$ are described in the footnotes. ${ }^{5}$ The 1977 actual and forecast values of the five land use categories are in Table 5 .

TABLE 5

1977 Ex Ante Forecast Performance

\begin{tabular}{|c|c|c|c|}
\hline Land Use & Actual & $\underline{\text { Forecast }}$ & $\% \triangle$ \\
\hline $\mathrm{A}_{\mathrm{T}}$ & 4605 & 4562 & -.9 \\
\hline $\mathrm{A}_{\mathrm{R}}$ & 2180 & 2070 & -1.8 \\
\hline$A_{C}$ & 270 & 268 & -.7 \\
\hline $\mathrm{A}_{\mathrm{I}}$ & 147 & 155 & 5.4 \\
\hline$A_{P}$ & 1468 & 1467 & .07 \\
\hline
\end{tabular}

$\% \Delta=\frac{\text { Forecast }- \text { Actual }}{\text { Actual }}$

An examination of Table 5 reveals that the model performed quite well with the exception of $A_{I}$. The percentage forecast error of $A_{T}, A_{C}$ and $A_{P}$ was less than $1 \%$ while that of $A_{R}$ was less than $2 \%$. 


\section{MODEL STRENGTHS AND WEAKNESSES}

There are some disadvantages to the approach taken by this model to forecasting land demand. Some of these problems are often inherent in time series regression models such as multicollinearity, autocorrelation, and forecasting the values of the independent variables. Also the time required to assemble the historical land use data is quite significant. This may be the main reason why this approach has not been tried before. It takes considerable time to measure the quantities of land in the various functional uses for a given year and this problem becomes increasingly significant the larger the size of the urban area and the larger the length of the estimation period. For all practical purposes this limits the application of the model to cities of moderate size, such as many of the cities in the "Sun Belt" that are now experiencing rapid growth.

While the model has these limitations it also has substantial advantages. By using local data, the model is able to capture the uniqueness of the local growth experience. This is in sharp contrast to other approaches which have applied national numeric averages, with a high degree of regional variation, to local situations. [For examples see Bartholomew 1955 and Davis 1974.]

Also the model is flexible in the sense of being able to estimate the impact of a wide variety of assumed alternative futures. For example, the extent of local growth will depend on the strength and nature of national demand. Therefore by making alternative forecasts of national demand, the differential impact on local employment and land use can be estimated. The land use impacts of alternative forecasts of the demand for higher education services as reflected in enrollment could also be simulated. Alternative assumptions with respect to fuel prices could also be made and their land use impacts evaluated. By making these alternative, conditional forecasts the sensitivity of land demand to the various causative factors can be determined.

The model can determine the range of probable local growth by making alternative assumptions with respect to the magnitudes of the important economic variables. This is very important to local policy makers because it allows them to begin developing plans for the right set of problems. If the prognosis for the community is slow growth or stagnation, local policy makers may begin thinking about how to attract new firms to the area or ways to offset the rising per unit public service costs that accompany stagnation. On the other hand, if the alternative forecasts yield a range of substantial growth, local policy makers have a different set of potential difficulties to plan for. They would likely have to consider ways of avoiding potential external costs and plan ways of financing additional public goods.

\section{REFERENCES}

Babcock, Michael W. 1977. "An Econometric Model of the Demand for Urban Land." Journal of Economics Proceedings of Missouri Valley Economic Association III: 161-163.
Bartholomew, Harland. 1955. Land Uses in American Cities. Cambridge, Mass.: Harvard University Press.

David, R. M. Et. al. 1974. "Development of an 
Economic-Environmental Trade-Off Model for Industrial Land L'se Planning." Reriew of Regional Studies I (Spring): 11-26.

Kelejian, H. H. and Oates, W. E. 1974. Introduction to Econometrics. New York, N. Y.: Harper \& Row.

Maddala, G. S. 1977. Econometrics. New York, N. Y.: McGraw-Hill.
Muth, R. F. 1961. "Spatial Structure of the Housing Market." Papers and Proceedings, Regional Science Association I: $207-220$

Pindyck, R. S. and Rubinfeld, D. L. 1976. Econometric Models and Economic Forecasts. New York, N. Y.: McGraw-Hill.

\section{FOOTNOTES}

${ }^{1}$ Employment data for Riley County were used because separate data for Manhattan aren't available. But since $75 \%$ of the Riley County population lives in Manhattan, this was not thought to be a serious problem.

${ }^{2}$ The state was used to estimate the trend in variable $\mathrm{C}$ due to the large number of transients in the local area. Large numbers of college students and military personnel operate cars in the local area, but they are not registered in the local jurisdiction. A more accurate assessment of the trend could be made by using the larger area assuming there are no large differences in transportation cost within the state.

${ }^{3} \mathrm{~N}$, and $\mathrm{N}_{1}$ - Kansas Department of Labor, Research and Analysis Section, Bureau of Employment Security.

$\mathrm{N}[\mathrm{US}]_{1}$ - U.S. Department of Labor, Bureau of Labor Statistics, Employment and Earnings, Table B-I (Washington, D.C.: U.S. Government Printing Office, July, 1976).

E - Office of Admissions and Records, Kansas State University.

C - Motor Vehicle Manufacturers Association, Auto Facts and Figures (Detroit, Michigan: Automobile Manufacturers Association).

Kansas State Board of Agriculture, Population of Kansas, Topeka, Kansas.

${ }^{4} \mathrm{~N}[\mathrm{~K}]$ - Kansas Department of Labor, Research and Analysis Section, Bureau of Employment Security.

N[US] - U.S. Department of Labor, Bureau of Labor
Statistics, Employment and Earnings, Table B-I (Washington, D.C.: U.S. Government Printing Office, February 1977).

E[REG] - Office of Admissions and Records, Kansas State University and U.S. Department of H.E.W., Office of Education, Opening Enrollment in Higher Education. (Washington, D.C.: U.S. Government Printing Office.)

E[SEN] - Kansas State Department of Education, School Finance and Statistics Department.

$\mathrm{Y}[\mathrm{K}]$ - U.S. Department of Commerce, U.S. Bureau of Economic Analysis, Survey of Current Business (Washington, D.C.: U.S. Government Printing Office).

${ }^{5} \mathrm{~N}-\mathrm{N}$ [US] was forecast by prorating the 1980 Bureau of Labor Statistics forecast found in Tomorrow's Manpower Needs, Bulletin 1737. E was forecast from equation (8) of the model. The forecast of $\mathrm{N}[\mathrm{K}]$ was taken from 14th annual Economic Report of the Governor - State of Kansas.

$\mathrm{N}_{1}-\mathrm{N}[\mathrm{US}]_{1}$ was forecast in the same manner as $\mathrm{N}[\mathrm{US}]$.

E - The forecast of E[REG] was furnished by the Board of Regents - State of Kansas. E[SEN] was forecast by using data furnished by the Kansas State Department of Education, School Finance and Statistics Department.

$\mathrm{C}$ - The forecast of $\mathrm{Y}[\mathrm{K}]$ was obtained from the same source as $\mathrm{N}[\mathrm{K}]$. Kansas population was forecast by using past growth rates. 